\title{
"Profesional, madre y trabajadora": significados de la igualdad de género entre mujeres universitarias y profesionales de la ciudad de Santiago de Chile ${ }^{1}$
}

\author{
Carmen Gloria Godoy Ramos ${ }^{2}$
}

Fecha de recepción: 23 de noviembre de 2017

Fecha de aprobación: 26 de marzo de 2018

\begin{abstract}
Resumen
En el presente trabajo abordamos los significados que mujeres jóvenes de la ciudad de Santiago de Chile, de entre 19 y 38 años y pertenecientes a las capas medias y altas, otorgan a la igualdad de género en la construcción de sus proyectos de vida y en sus prácticas cotidianas, en el ámbito familiar, educativo y laboral. A partir del análisis de 25 entrevistas semiestructuradas, realizadas entre 2014 y 2015 a mujeres profesionales y a estudiantes de universidades privadas y del Consejo de Rectores de las Universidades Chilenas (CRUCH), buscamos comprender algunos aspectos de la cristalización de normas, valores, imágenes y estereotipos respecto de los roles femenino y masculino que se han venido desarrollando en Chile durante las últimas décadas, y cómo se despliegan en esferas diferenciadas que se articulan sobre el eje de lo privado y lo público, en tanto involucran proyectos personales, relaciones familiares y de pareja.
\end{abstract}

Palabras clave: mujeres, igualdad de género, familia, educación, trabajo.

Este artículo se desprende de los resultados del Proyecto FONDECYT de Iniciación en Investigación $N^{\circ} 11130005$ (2013-2016), financiado por la Comisión Nacional de Investigación Científica y Tecnológica, CONICYT: “El discurso de la igualdad de género en Chile y su recepción en mujeres jóvenes de las capas medias y altas". Investigadora responsable: Carmen Gloria Godoy Ramos.

2 Doctora en Estudios Latinoamericanos, Universidad de Chile. Antropóloga de la Universidad Academia de Humanismo Cristiano. Profesora Escuela de Historia, Facultad de Ciencias Sociales e Historia, Universidad Diego Portales, Santiago, Chile. Contacto: cggodoy82@hotmail.com 


\title{
"Professional, mother and hard-worker:" Meanings for gender equality among professional and university women at Santiago de Chile
}

\begin{abstract}
The present work addresses meanings given by middle and upper-class Chilean young women between 19 and 38 years old to gender equality at constructing their life projects and in their daily practices, in family, educational and work environment. By the analysis of 25 semi-structured interviews applied between 2014 and 2015 to students and professional women from private universities and the Council of Rectors of Chilean Universities (CRUCH), we seek to understand some aspects of the crystallization of norms, values, images and stereotypes regarding female and male roles developed in Chile during the last decades, and how they are viewed in differentiated private and public spheres, involving personal projects, family and couple relationships.
\end{abstract}

Keywords: Women, gender equality, family, education, work

\section{"Profissional, mãe e trabalhadora": Significados da igualdade de gênero entre mulheres universitárias e profissionais da cidade de Santiago do Chile}

\begin{abstract}
Resumo
No presente trabalho abordamos os significados que mulheres jovens da cidade de Santiago do Chile, dentre 19 e 38 anos e que pertencem às classes médias e altas, conferem à igualdade de gênero na construção dos seus projetos de vida e nas suas práticas cotidianas, no âmbito familiar, educativo e laboral. A partir da análise de 25 entrevistas semiestruturadas, realizadas entre 2014 e 2015 a mulheres profissionais e a estudantes de universidades privadas e do Conselho de Reitores das Universidades Chilenas (CRUCH), buscamos compreender alguns aspectos da cristalização de normas, valores, imagens e estereótipos a respeito dos papéis feminino e masculino que se têm vindo desenvolvendo no Chile durante as últimas décadas, e como é que se desenrolam em esferas diferenciadas que se articulam sobre o eixo do privado e o público, enquanto envolvem projetos pessoais, relações familiares e relacionamentos afetivos.
\end{abstract}

Palavras-chave: mulheres, igualdade de gênero, família, educação, trabalho

\section{Introducción}

En este trabajo abordamos los significados que un grupo acotado de mujeres de entre 19 y 38 años le otorgan a la igualdad de género en la construcción de sus proyectos de vida y en sus 
prácticas cotidianas, en el ámbito familiar, educativo y laboral. Nos interesa comprender algunos aspectos de la cristalización de normas, valores, imágenes y estereotipos respecto de los roles femenino y masculino que se han venido desarrollando en Chile durante las últimas décadas, y cómo se despliegan en esferas diferenciadas que se articulan sobre el eje de lo privado y lo público, en tanto involucran proyectos personales, relaciones familiares y de pareja.

El análisis que presentamos se basa en los resultados de una investigación desarrollada entre 2013 y 2016, cuyo propósito era caracterizar el discurso en torno a la igualdad de género que emerge en Chile desde la década de 1990 y su recepción en mujeres jóvenes, universitarias y profesionales, de las capas medias y altas de la ciudad de Santiago de Chile. Tres preguntas de investigación sustentaron dicho estudio, y apuntaban a conocer el grado de adhesión que genera la igualdad de género como referente discursivo, la influencia que adquieren los discursos públicos de igualdad de género en el despliegue de nuevas prácticas y en las relaciones de género entre estudiantes universitarias y profesionales, así como la posible incorporación del referente de la igualdad como derechos en el ámbito de la ciudadanía.

Es necesario señalar que, en Chile, el retorno a un régimen de gobierno de carácter democrático en 1990 señala el inicio de un período caracterizado por una serie de transformaciones en el ámbito de las prácticas y representaciones sexo-genéricas -en estrecha relación con la creación de una institucionalidad y la materialización de diversas iniciativas legales en dicho ámbito-, al mismo tiempo que con la transformación de los referentes de género y sexualidad (PNUD, 2010). La introducción de nuevos estilos de vida y prácticas sociales en "la familia, la política y la cultura, interpelaron a las instituciones vigentes y estimularon los procesos de individuación, que adquirieron especial importancia en el caso de las mujeres" (Guzmán, 2013, p. 203). La aprobación de marcos jurídicos internacionales sobre igualdad de 
género legitimó los argumentos feministas por incluir "nuevas concepciones e ideas sobre las relaciones de género en la institucionalidad pública" (Op. cit., p. 202)3.

Al mismo tiempo, se observa una continua resistencia y obstaculización a las expresiones de la diversidad sexual y la ampliación de los derechos de las mujeres -sobre todo en el ámbito sexual y reproductivo-, así como la defensa del modelo tradicional de familia como garante de la estabilidad social por parte de sectores que promueven una postura liberal en el terreno económico pero con una fuerte ligazón a una moral conservadora de raigambre cristiana (particularmente católica) (Delsig, 1997; Oyarzún, 2000; Olea, Grau y Pérez, 2000, Hurtado, Pérez y Dides, 2004; Thumala, 2007). Fue particular en relación a la discusión sobre la creación del Servicio Nacional de la Mujer (SERNAM) en el gobierno de Patricio Aylwin Azócar (1990-1996) que, entre parlamentarios de la coalición de derecha y senadores designados, se cuestionó el uso del término "género" y el debate que implicaba, ya que era asociado a una "ideología de izquierda" que propiciaba un sector "minoritario" de la sociedad (Godoy, 2013, p. 107)4. Con todo, y pese a las resistencias que supuso en su momento la introducción del género en el debate público y las limitaciones que encontraron las demandas de los movimientos sociales referidas a lo público y lo privado (Mora, 2013, p. 30), la "igualdad de género" llegó a instalarse como discurso, y a convertirse en un referente $\mathrm{u}$ horizonte de expectativas, un indicador, como plantea Iréne Théry (2004), del grado de democratización de la vida social.

\footnotetext{
3 La autora destaca la Convención sobre la Eliminación de todas las Formas de Discriminación contra la Mujer (CEDAW, 1979) y "la suscripción de las plataformas o programas de acción aprobados en las conferencias mundiales a partir de 1975" (Guzmán, 2013, p. 202, nota 3).

4 Ver, en relación a este tema: "De la lucha de clases a la lucha de géneros" (1995), de Lucía Santa Cruz, texto que hace referencia a la discusión suscitada por el Primer Plan de Igualdad de Oportunidades elaborado por el SERNAM.
} 
Desde esta perspectiva, el Observatorio de Igualdad de Género para América Latina y el Caribe plantea que son tres los pilares de la igualdad de género y de una ciudadanía basada en la paridad: i) autonomía económica (la capacidad para generar ingresos propios y controlar los activos y recursos); ii) la autonomía física (el control sobre el propio cuerpo); iii) la autonomía en la toma de decisiones (plena participación en las decisiones que afectan la vida de las mujeres y a su colectividad) (CEPAL, 2010, p. 38). Sin embargo, las posibilidades concretas de avanzar en la igualdad entre hombres y mujeres, en distintos ámbitos, van de la mano de una serie de desigualdades de carácter estructural que los afecta de distinta manera. Por un lado, la "igualdad de género" ha sido enmarcada en la igualdad de oportunidades como forma de justicia de social orientada a potenciar el mérito de los individuos y no necesariamente a cuestionar las posiciones que ocupan hombres o mujeres en la estructura social (Dubet, 2011). Así, en Chile, para un sector menos crítico de las políticas neoliberales, se pone el énfasis en valores como la libertad, el esfuerzo y la responsabilidad individual, desde la lógica económica, es decir, la inclusión en el mercado y la capacidad de consumo (Vergara, 1985; Moulian, 2002). Por otra parte, como plantea Claudia Mora, las demandas redistributivas que emergen con fuerza en la última década no incluyen necesariamente el género como forma de desigualdad social, ya que se naturaliza "una valoración diferenciada y jerárquica" correspondiente con "la división funcional de labores, legitimada por lo que se percibe como aptitudes diferenciadas entre hombres y mujeres, también objetivas, que hacen evidente y necesaria la especialización" (Mora, 2013, p. 26).

En este sentido, siguiendo la argumentación de Nancy Fraser, las desigualdades de género deben abordarse en su dimensión estructural, ligada al acceso diferenciado a los recursos, como en su dimensión simbólica, que se expresa en patrones culturales que legitiman la posición subordinada de lo femenino. De acuerdo con la autora, el género corresponde a "un eje categorial que abarca dos dimensiones del orden social": la distribución y el re- 
conocimiento, dimensiones que interactúan entre sí, aun manteniendo cierto grado de independencia (Fraser, 2013, pp. 162-163). La justicia de género se sustenta así en el principio de "paridad de participación", condición cualitativa que supone interactuar con otros como un par, como iguales (Op. cit., p. 166). Fraser agrega la "representación" como una tercera dimensión de la justicia de género, que demanda no solo la participación política de las mujeres en "comunidades políticas ya constituidas", sino también "reenmarcar los debates sobre justicia" (2008, p. 204). Es decir, pasar de un marco estatal territorial a una fase transnacional de la política feminista (Op. cit., pp. 206-207).

Como señalábamos, se han producido importantes cambios en los procesos de individuación y modernización de la sociedad chilena (Tironi, 2005; Valdés, 2007b; Araujo y Martucelli, 2012), así como en las prácticas y representaciones sexo-genéricas que se consignan especialmente entre mujeres menores de 40 años, en el marco de transformaciones estructurales vinculadas a la implementación de un sistema de libre mercado. Se trata de cambios que consolidan la opción profesional, sobre todo para los sectores medios y altos. La tasa de participación laboral femenina era en 1970 de un 19,7\%, registrando un ascenso importante desde los ochenta en adelante (Valdés, 2007, p. 161), hasta llegar a un 28,1\% en 1992, 35,7\% en 2002 (Tironi, 2003, p. 15-76) y 48\% a 2015 (Comisión Nacional de Productividad, 2017) 5 . Si bien continúa siendo baja en comparación con la de otros países de la región ${ }^{6}$, el incremento de la fuerza de trabajo femenina se explica por la mayor incorporación de las mujeres de los estratos socioeconómicos superiores, es decir, entre quienes poseen educación media y técnica o superior-universitaria completa (Tironi, 2003, pp. 3536). El aumento de la fuerza de trabajo femenina trajo consigo

\footnotetext{
5 La brecha por sexo es de -23,3\% (http://www.ine.cl/estadisticas/menusociales/genero).

6 La tasa de participación femenina en América Latina y el Caribe alcanza un $53 \%$, si bien se encontraría estancada y presenta grandes brechas en el acceso a oportunidades entre hombres y mujeres (CEPAL, 2016).
} 
la transformación del proyecto de vida centrado exclusivamente en la maternidad y la familia. De este modo, mujeres con hijos y con mayor nivel educacional se han incorporado al mercado laboral, al mismo tiempo que el aumento de la escolaridad ha retardado las uniones matrimoniales (Valdés, et al., 2006, p. 26; Valdés, 2007).

La participación en el mercado laboral está estrechamente relacionada con los años de escolaridad: mujeres con más años de educación formal y mayores recursos económicos tienen mayor participación, lo cual se relacionaría con decisiones familiares "basadas en aspectos morales y sociales [que] varían según grupo social" (Duncan et al., 2003; Undurraga, 2013, p. 115). En este sentido, la educación superior universitaria es un ámbito en el que, en Chile, durante la última década, la presencia femenina se hace cada vez más importante. En 2014, según datos del Servicio de Información de la Educación Superior (SIES), la matrícula de estudiantes en la educación superior (incluyendo institutos profesionales y centros de formación técnica) fue de 1.215.413, de los cuales un 52\% era de mujeres (Godoy, 2016, p. 124). Por otro lado, de acuerdo con información del Ministerio de Educación sobre matrícula universitaria de mujeres entre 1983 y 2011, y en concordancia con el panorama regional, las áreas de Salud, Ingeniería, Economía y Negocios y Ciencias Sociales tuvieron un crecimiento constante -particularmente salud y tecnología-, de tal modo que para 2011 el número de mujeres matriculadas y tituladas superaba al de los varones, si bien en ciertas áreas se concentraba la matrícula femenina (Op. cit., p. 125).

Como plantea Sonia Montecino, en las últimas décadas las mujeres se han desplazado desde la casa a la calle, "usurpando" espacios privativos del mundo masculino (2007, p. 157). Ocupar esos espacios supone reacomodos, aprender códigos diseñados por otros, los que, aunque conocidos, no se manejan "diestramente" (Op. cit., p. 158). Desde esa perspectiva, es posible reflexionar sobre los cambios culturales en el ámbito de las concepciones de lo femenino y masculino entre las nuevas generaciones de mujeres 
-que han accedido a mayores niveles educacionales durante las últimas décadas y se desempeñan en el mundo laboral-, los sentidos que se otorga a este desplazamiento de lo privado a lo público, el aprendizaje de las reglas, así como la articulación de lo público y lo privado en cuanto a sus experiencias familiares, personales y profesionales. Y, en ese contexto, la importancia y sentidos que se otorga a la igualdad de género como principio que cuestiona las "prácticas naturalizadas" en el campo sexo-génerico.

\section{Aspectos metodológicos}

El artículo se enmarca en una investigación cualitativa (Hernández, Fernández y Baptista, 2003) con un enfoque interpretativo, cuyo objeto es profundizar en la recepción de los discursos de igualdad de género a partir del supuesto de que esta recepción no se produce de manera homogénea, sino que en ella se articulan diversos factores expresados en las narrativas de los sujetos involucrados, en este caso, "mujeres que se encuentran estudiando una carrera universitaria y aquellas que ya se han incorporado al mercado laboral como profesionales".

La investigación se realizó en la ciudad de Santiago de Chile. La principal técnica de recolección de información fue la entrevista semiestructurada; también se analizaron fuentes documentales primarias y secundarias relativas al discurso oficial sobre igualdad de género y los hitos relevantes en su institucionalización durante el periodo 1990-2013, así como revistas/suplementos de circulación nacional dirigidas particularmente al público femenino.

El trabajo que desarrollamos en los apartados siguientes se basa en el análisis de 25 entrevistas realizadas entre 2014 y $2015^{7}$ a

$7 \quad$ La muestra total del estudio corresponde a 47 mujeres e incluye entrevistas a quienes participaban de centros de estudiantes y/o federaciones en universidades del CRUCH, y en universidades del sistema privado, cuyas edades fluctúan entre los 20 y 31 años; así como mujeres profesionales entre 23 y 40 años, que formaban parte 
13 estudiantes de entre 19 y 28 años, de universidades privadas y del Consejo de Rectores de las Universidades Chilenas (CRUCH) (tabla 1); y a 12 mujeres profesionales de entre 25 y 38 años (tabla 2). Se trata de una muestra intencionada no probabilística, que incluye un conjunto de mujeres que comparten entre sí características relevantes para la investigación: mujeres de entre 18 y 40 años, pertenecientes a las capas medias y altas, que se encontraran estudiando una carrera universitaria (en nivel inicial o avanzado) y fuesen profesionales con empleo remunerado. Todas las entrevistas se realizaron previa firma de un consentimiento informado.

Tabla 1. Universitarias ${ }^{8}$

\begin{tabular}{|l|c|c|c|c|c|}
\hline \multirow{2}{*}{ Edad } & \multirow{2}{*}{$\begin{array}{c}\text { Capas } \\
\text { altas }\end{array}$} & \multirow{2}{*}{$\begin{array}{c}\text { Capas } \\
\text { medias }\end{array}$} & \multicolumn{2}{|c|}{$\begin{array}{c}\text { Universidad en que } \\
\text { estudia }\end{array}$} & \multirow{2}{*}{$\begin{array}{c}\text { Con } \\
\text { Hijos }\end{array}$} \\
\cline { 4 - 5 } & & & CRUCH & Privada & \\
\hline $19-23$ & 4 & 2 & 3 & 3 & 1 \\
\hline $24-28$ & 3 & 4 & 4 & 3 & 0 \\
\hline Total & 7 & 6 & 7 & 6 & 1 \\
\hline
\end{tabular}

Tabla 2. Profesionales ${ }^{9}$

\begin{tabular}{|l|c|c|c|c|c|}
\hline \multirow{2}{*}{ Edad } & \multirow{2}{*}{$\begin{array}{c}\text { Capas } \\
\text { altas }\end{array}$} & \multirow{2}{*}{$\begin{array}{c}\text { Capas } \\
\text { medias }\end{array}$} & \multicolumn{2}{|c|}{$\begin{array}{c}\text { Universidad en que } \\
\text { estudió }\end{array}$} & \multirow{2}{*}{ Con Hijos } \\
\cline { 4 - 5 } & & & CRUCH & Privada & \\
\hline $25-31$ & 2 & 4 & 4 & 2 & 0 \\
\hline $32-38$ & 4 & 2 & 2 & 4 & 4 \\
\hline Total & 6 & 6 & 6 & 6 & 4 \\
\hline
\end{tabular}

Para la selección de las entrevistadas, tanto universitarias como profesionales, se intentó privilegiar y mantener un equilibrio entre carreras y profesiones inscritas en áreas de cono-

de organizaciones de carácter feminista y lesbofeminista, así como en organizaciones sindicales y políticas.

8 No se incluye el estado civil; las entrevistadas eran solteras, independiente de su situación de pareja.

9 No se incluye el estado civil; las entrevistadas se encontraban solteras, independiente de su situación de pareja, a excepción de una de ellas, divorciada. 
cimiento que, por un lado, han tenido históricamente menor presencia de mujeres y son calificadas como masculinas, así como aquellas con una marcada presencia femenina. Esto de acuerdo con los datos obtenidos sobre universidades y carreras impartidas en el sistema de educación superior (Godoy, 2016) y con la evolución de la matrícula femenina y masculina por área de conocimiento y carreras en el ingreso a universidades del CRUCH, como a universidades privadas desde 1990. Del mismo modo, buscamos mantener cierta coherencia entre las áreas de conocimiento a las que pertenecen carreras y profesiones y entre las universidades del CRUCH y privadas en las que estudian o estudiaron las entrevistadas, de manera que se pudiera visualizar elementos en común y diferencias en las opciones profesionales y en el entorno en el cual se desenvuelven o desenvolvieron las entrevistadas.

Las entrevistadas universitarias se encontraban cursando las carreras de: Tecnología Médica, Ingeniería en Agronegocios, Ingeniería en Minas, Medicina, Bachillerato, Licenciatura en Biología, Geología, Derecho, Licenciatura en Historia, Enfermería, Trabajo Social, Terapia Ocupacional. Mientras que las profesionales se habían titulado y/o licenciado en: Trabajo Social, Arquitectura, Psicología, Ciencias Políticas, Periodismo, Ingeniería Comercial, Medicina, Licenciatura en Historia, Administración Pública.

La pertenencia a cada grupo social se determinó a partir de los ingresos propios o familiares, la comuna de residencia y el nivel educacional de los padres, información obtenida por medio de un cuestionario de caracterización socioeconómica. Del total de entrevistadas, 13 corresponden a mujeres de capas altas (7 universitarias y 6 profesionales), mientras que 12 a capas medias (6 universitarias y 6 profesionales). Para efectos de este artículo, tendremos en cuenta algunos aspectos relacionados con la pertenencia social, pero abordaremos con mayor profundidad las diferencias y similitudes en las experiencias y los sentidos atribuidos a la igualdad de género de modo global. 
El número de hijos y el estado civil no fueron criterios de selección, pero entre las entrevistadas se cuentan mujeres con y sin hijos, con o sin pareja al momento de la entrevista, prácticamente en su totalidad solteras, con excepción de un caso -entre las profesionales- que correspondía a una mujer divorciada. Entre las profesionales, varias contaban con estudios de posgrado o especializaciones posteriores a la obtención del título profesional y/o grado académico, todas tenían un empleo, ya sea cumpliendo con una jornada o por horas. Entre las universitarias se cuentan varias egresadas y/o en proceso de titulación, que habían realizado ya sus prácticas profesionales, contaban con un empleo antes de iniciar sus estudios o trabajaban esporádicamente para generar algunos ingresos.

Las entrevistas se organizaron en relación con una serie de temas y subtemas, mediante los cuales se buscaba generar un relato que permitiera, por un lado, articular la relación entre lo público y lo privado en la experiencia de las entrevistadas y, por otro, comprender el sentido y la importancia que le otorgaban al discurso de la igualdad en los distintos ámbitos en que se desenvuelven cotidianamente y según los recursos (materiales y tecnológicos) a los que tienen acceso. Los temas y subtemas se desglosan del siguiente modo: 1) experiencia familiar, personal y prácticas cotidianas en relación con la igualdad de género (familia, pareja, maternidad; construcción de lo femenino; sociabilidad); 2) nivel educacional y trayectoria laboral (educación, trabajo); 3) porosidad frente a nuevas concepciones de género y derechos de las mujeres (avances y derechos de las mujeres; redes sociales y medios de comunicación).

En los apartados siguientes desarrollamos el análisis de las entrevistas en torno a tres ejes: la experiencia familiar, la experiencia educativa y la experiencia laboral. En cada uno de ellos problematizamos significados y creencias que resulten comunes para las entrevistadas, distinguiendo, cuando es necesario, la visión de universitarias y profesionales. Finalmente, presentamos algunas reflexiones a modo de conclusión. 


\section{Análisis ${ }^{10}$}

Retomamos el planteamiento de Joan Scott respecto del género como "una forma primaria de relaciones significantes de poder" (1990, p. 47). El campo por medio del cual o en el cual se articula el poder. Este es un aspecto importante para comprender la porosidad ante las nuevas concepciones de lo femenino y lo masculino, los sentidos que se otorgan a la idea de igualdad, los modos de llevarla a la práctica y las formas en que se configuran las asimetrías en las relaciones al interior de la familia y entre pares, tanto en el espacio educativo como en el laboral.

Pedimos a las entrevistadas que se refirieran a la igualdad de género, ya sea definiéndola o reflexionando sobre sus alcances en la actualidad. Las respuestas iban en direcciones opuestas: por un lado, era presentada como un ideal, un horizonte de expectativas que, en la práctica, no necesariamente se concreta; por otro, como una situación de hecho: "hombres y mujeres somos iguales", "ambos tenemos las mismas capacidades" para ocupar cualquier posición. En ambas direcciones se consideraba que la situación de las mujeres, en general, había mejorado en relación con la experiencia de sus madres y abuelas. No obstante, esa igualdad se desplegaba de distinto modo si se trataba de la familia, el trabajo o los estudios, así también de acuerdo con sus propias historias familiares.

De acuerdo con lo anterior, reconocen mayor receptividad de la sociedad frente a la presencia de las mujeres en el espacio público, el desplazamiento de las fronteras rígidas entre lo masculino y lo femenino, así como respecto de temas que durante mucho tiempo fueron parte de las demandas de las organizaciones de mujeres y particularmente de los movimientos feministas, como

\footnotetext{
10 En las citas identificamos a las entrevistadas como EU (Entrevistada Universitaria) o EP (Entrevistada Profesional), indicando la edad, profesión o la carrera que estudian, y el nivel en que se encuentran (semestre/año), su pertenencia a las capas medias o altas y, si corresponde, número de hijos.
} 
es la participación en el mundo del trabajo y la política, y especialmente la autonomía sobre el cuerpo. Desde esta perspectiva, reconocer el machismo, la violencia, el acoso sexual, las brechas salariales, etc., suele ir acompañado en sus respuestas de una precisión que brota casi de manera espontánea: no ser feministas. Si bien algunas estudiantes y profesionales se reconocen como feministas o, al menos, cercanas a sus postulados, varias consideran que identificarse como tales significa adoptar una postura radical y extremista, que muchas equiparan (por una mala comprensión o desconocimiento) como equivalente al machismo, que tiende a profundizar las diferencias entre hombres y mujeres (a través de las cuotas políticas, por ejemplo), pregonando la superioridad femenina en lugar de equiparar posiciones. Por otro, puede ser motivo de cuestionamiento por parte de sus pares (ser tildadas de "feminazi"11), sobre todo entre las estudiantes universitarias. Mientras que entre las profesionales tendría como consecuencia no ser reconocidas por sus méritos e, inversamente, ser vistas como débiles y menos capaces.

En este contexto, tanto en el caso de universitarias como de las profesionales, la posibilidad de generar un proyecto de vida propio (ya sea orientado al desarrollo profesional, la maternidad u otros proyectos personales), en el que la independencia económica adquiere centralidad, aparece como una de las principales transformaciones relativas a la concreción de la igualdad de género, así como la posibilidad y el deseo de ser exitosas profesionalmente:

(...) antes las mujeres si no estudiaban, no era pecado, ahora es como "¿no estás estudiando?", o sea, en mi mundo es como "¿no vai a estudiar después del colegio?", o sea, es normal, a mí me llama la atención si al-

\footnotetext{
11 Término utilizado para referirse de manera peyorativa a las mujeres feministas: “alude también a que el feminismo utiliza la exageración como mecanismo para neutralizar a los hombres". El término nació en la década de 1990 y fue popularizado por un político conservador estadounidense (Cumplido, 2014).
} 
guien me dice "no, voy a trabajar al tiro", no, cachai, yo sé que después del colegio viene la [universidad] (...) Antes igual las mismas mujeres eran como sometidas, se quedaban calladas en el matrimonio, no sé, las podían maltratar, y se quedaban ahí calladas, o en el mismo pololeo, ahora si te llegaran a levantar la mano se entera todo el mundo poh, y yo igual soy así, si me pasa algo, tengo un problema, no me voy a quedar callada, lo voy a decir. (EU, 27 años, estudiante de Geología, sexto semestre, capas altas)

Me imagino ser totalmente independiente económicamente por lo menos, no mezclar platas (...) mi idea es hacer una carrera exitosa que tenga remuneraciones altas para mantener a los hijos que quiera tener, sola, y ojalá con alguien más y por lo tanto que sea más, pero ser autosuficiente". (EU, 19 años, estudiante de Bachillerato, capas altas)

No obstante, se reconoce que, pese a que se han conseguido ciertas libertades, también aparecen nuevas presiones, barreras y obstáculos, que se manifiestan, en general, en el terreno económico y, particularmente, cuando se es madre sola y trabajadora, debido a los costos económicos que esta decisión puede traer consigo. Paradojalmente, y como veremos más adelante, pese a la alta valoración social de la maternidad y que las entrevistadas afirmen que no la sienten como una obligación por el hecho de ser mujeres, aún perciben ciertas presiones de su entorno si manifiestan que no desean ser madres.

(...) las mujeres, como que ya deciden cuando quieren ser mamás, yo creo que antes existía eso en la familia de "¿cuánto te vas a casar? ¿Cuándo vas a tener hijos?", como esa presión, como que siempre pregunta la gente, y a los hombres yo no recuerdo que les pregunten "oye, ¿cuándo...?", a no ser que sean mucho mayores, como adultos, cuarenta años, “¿cuánto te vas a casar, cuándo 
vas a tener hijos?", en cambio a las mujeres, tienen como veintitantos o si pololean, no sé, dos o tres años, está esa presión, así como “¿cuándo se van a casar, cuándo van a tener hijos?", yo creo que a la mujer le llega más eso que a los hombres. (EU, 24 años, estudiante de Tecnología Médica, décimo semestre, capas medias)

\subsection{La experiencia familiar}

En los relatos de las entrevistadas emergen ciertas contradicciones en torno a las dinámicas familiares respecto de las relaciones entre hermanos/as -las libertades, responsabilidades y tareas asignadas-, aun cuando hay un grado de reflexividad sobre el rol transmitido y aprendido. La experiencia familiar y la relación con padres y hermanos (sobre todo entre estudiantes que aun residen con ellos) tiende a influir en la concepción de los roles de género y la elección profesional. Incluso de manera negativa o como resistencia a las normas impuestas. Es así que las respuestas de las entrevistadas denotan una recepción positiva a las nuevas concepciones de género, en cuanto a la desnaturalización de los roles y las relaciones más igualitarias entre hombres y mujeres, en las que la presencia de padre y madre trabajadores resulta clave. Cabe destacar que las hijas recibieron y/o reciben mensajes acerca de la importancia de la educación y el trabajo; esto se observa especialmente entre quienes tienen una madre profesional y con una situación más acomodada, dado que el paso de la etapa escolar a la universitaria y luego a la especialización o formación en posgrado aparece como un pasaje "natural" e incuestionable.

(...) esa era como la visión de futuro de mi mamá, que fuera profesional, que estudiara, que fuera mejor que ella para que yo trabajara, tuviera mi plata independiente, no dependiera, pero en el fondo que esos ingresos no fueran para mantener una casa, sino que fueran para mí. (...) "trabaja, sé independiente, nunca dejes de trabajar, yo dejé de trabajar y tengo que pedirle plata para todo a 
tu papá y es súper fome", esa era como la dinámica, en el fondo trabajar para tener tu plata y comprarte tus cremas, tus cosas, como siempre la dinámica más femenina ¿cachai? (EP, 38 años, ingeniera comercial, capas altas, 1 hijo)

No obstante, como observamos en la cita, ser profesional y contar con un ingreso propio, más que sustentar económicamente el hogar, permite mantener una "dinámica femenina", aun cuando esta se traduzca en el consumo de productos de belleza. Esto, que podría entenderse como un cambio superficial, supone también generar cierto grado de autonomía de la pareja (particularmente en parejas que se conformaron entre las décadas de 1970 y 1980, como es el caso de los padres de las entrevistadas) y contar con un dinero propio que también puede servir para afrontar algún tipo de emergencia económica. De este modo, los estudios y el trabajo se promueven como un medio para obtener independencia, asegurar su bienestar y evitar la dependencia del marido, en este caso, valorándose como una forma de desarrollo personal. Si bien no siempre de manera explícita, emerge aquí el ideal de una mujer moderna acorde con las transformaciones socioeconómicas ocurridas: profesional, madre y trabajadora.

(...) yo hoy tengo 28, pienso que es importante [trabajar] para una mujer de 28, como para una mujer de 60 (...) es súper importante [el trabajo], no solo por plata, sino que por realización personal, y más aún cuando tú estudiaste algo y te quedaste sin nunca hacer nada, ¿me entiendes?, o sea, que yo mañana me casara con alguien que tiene mucha plata (...) pero qué voy a hacer todo el día, cuidar a los niños (...), es súper importante, como por realización personal de la mujer, por moverte, por no envejecerte, por relacionarse también (...) ¿te imaginas no haciendo nada? (EU, 28 años, estudiante de Ingeniería en Agronegocios, en proceso de titulación, capas medias) 
Luego, encontramos el caso de mujeres que son las primeras de su familia en acceder a estudios universitarios y a las cuales se les inculcó desde pequeñas que debían estudiar para convertirse en profesionales, acceder también a mejores opciones laborales y, con ello, a una vida con un mayor bienestar:

(...) la idea de ser profesional siempre estuvo en mi crianza, o sea, siento que en el fondo a mí me criaron para llegar a lo que soy ahora, porque yo soy la primera mujer en mi familia en tener un estudio universitario, y la primera de mi familia también mujer en tener un grado o un magíster, entonces igual es un tema ese. Y a mí me costó mucho, por un tema financiero, pero aun así se inculcó que tenía que estudiar, tenía que estudiar, tenía que sacarme buenas notas. (...), a uno le puede ir súper bien, pero a veces cuesta, hay que esforzarse más que el resto, y a mí me tocaba a veces esforzarme más que el resto, pero aprendí de las mejores, que en este caso mi abuelita más que nada, y mi mamá también en parte. (EP, 27 años, periodista con grado de maestría, capas medias)

En este sentido, se deslizan críticas a aquellas mujeres de la familia que optaron por dejar sus carreras profesionales para dedicarse al cuidado de los hijos y las tareas domésticas. Aun cuando existe cierta ambigüedad en este aspecto, ya que también se valora fuertemente la maternidad (como identidad) y el rol materno en su dimensión de sostenedora del hogar. En relación con las diferencias sociales, económicas y religiosas, y su influencia, las dos primeras resultan importantes en el modo en que se elaboran las concepciones acerca de la igualdad y se vinculan estrechamente a la propia historia familiar y su nivel socioeconómico:

(...) yo creo que la clase media y media alta han sido las más como modificadas en ese sentido, porque no creo que la clase alta haya tenido nunca tan "la mujer tiene que dedicarse a la familia", ¿cachai?, porque siempre 
han tenido como los recursos para poder elegir, en cambio las mujeres de clase baja han tenido, yo creo, más dificultades en ese sentido, de partida lograr entrar a la educación cuando es de clase baja, igual es mucho más complicado, entonces supongo qué onda, juntar para una mujer: maternidad, estudios, de clase baja, es casi imposible, o sea, muy difícil. (EU, 19 años, estudiante de Biología, segundo semestre, capas altas)

Pero no solo porque el nivel de ingresos se traduzca necesariamente en un mayor nivel cultural y adhesión al discurso de la igualdad (muchas veces las posturas de padres y hermanos pueden ser conservadoras en algunos aspectos), sino también porque el esfuerzo por asegurar el bienestar económico obliga a redistribuir los roles entre el padre y la madre (o las figuras cuidadoras, que también pueden ser abuelos/as); por lo tanto, generan un punto de inflexión en cuanto a los modelos tradicionales. Por ejemplo, en relación con los ingresos de la pareja:

(...) hubo un tiempo en que mi mamá trabajaba vendiendo departamentos que valían como un millón de dólares, entonces hubo varios meses que mi mamá ganó mucho más que mi papá, no alcanzó a ser un problema familiar, pero yo sí sentía que habían discusiones que eran motivo de eso. Yo nunca sentí que mi mamá le tirara en cara nada, pero mi papá lo sacaba como a colación, o sea, a veces decía, así como "ya, si esta situación va a cambiar...". (EU, 28 años, estudiante de Ingeniería en Agronegocios, en proceso de titulación, capas medias)

Como decíamos, si bien en la mayoría de los casos nos encontramos con una redistribución del trabajo doméstico y el cuidado de los hijos y/o personas dependientes, cuando el padre está presente y tanto él como la madre son empleados o generan sus propios ingresos, algunas entrevistadas relatan situaciones en las que persiste una concepción tradicional y machista sobre los deberes de las mujeres en el hogar, que se expresa en actividades 
cotidianas, como servir la mesa, calentar la comida, quedarse a cargo de las labores de limpieza si la madre no está, etc. Al mismo tiempo, se reconocen contradicciones en las libertades otorgadas a los hermanos (horarios de salida y llegada) y un mayor control tanto de parte del padre como la madre durante la adolescencia, que es posible eludir una vez que se ingresa a la universidad. En este escenario, la generación de ingresos propios permite hacerse un lugar y una voz que se escucha en la familia.

(...) por suerte yo tengo una posición bien validada dentro de mi familia, por decirlo de algún modo, soy capaz de expresar mis argumentos en la mesa, también como... algo súper pesado, pero como gano lucas y ayudo en mi casa, o sea, ayudo a mis abuelos, ayudo a mi mamá, eso también me da un peso de valor en el discurso y que está vinculado con el machismo: el que puede proveer, puede hablar. (EP, 31 años, asistente social, capas medias)

\subsection{La experiencia educativa y laboral}

En este apartado nos enfocamos en algunos aspectos que consideramos relevantes respecto de la experiencia de universitarias y profesionales. En el caso de las primeras, nos centramos en sus proyecciones laborales y la autonomía económica. En relación con las profesionales, abordamos dos situaciones: reconocimiento y visibilización.

\section{La experiencia educativa}

La dinámica familiar se articula con la experiencia escolar y el carácter del establecimiento educacional en el cual las entrevistadas cursaron sus estudios básicos y medios, que corresponde tanto a colegios particulares pagados, religiosos y laicos, o más cercanos a un modelo educativo menos convencional, como a establecimientos municipales (liceos de mujeres o mixtos con una larga historia de excelencia académica). 
Un factor importante en la comprensión de la igualdad de género y en su elaboración, tanto en el ámbito familiar como educativo y laboral, son las relaciones que se establecen entre pares y con las figuras de autoridad (padres, hermanos/as, profesores/as, jefes/as), las que van modelando la inserción de las mujeres en lo público, los reacomodos en lo privado y el modo de significar los roles tradicionales. En este sentido, el "conocimiento" de la igualdad de género se adquiere más bien en la experiencia, a través de los debates que se difunden en los medios de comunicación con relación a ciertos acontecimientos (por ejemplo, casos de femicidios, acoso sexual) más que por medios institucionales -particularmente la escuela entre las entrevistadas mayores de 35 años-, ya que en la universidad se puede tener acceso a más información.

Es así como, en muchos casos, se evidencia desconocimiento en relación con la emergencia de las demandas históricas sobre ampliación de derechos de las mujeres y, a menos que se maneje un discurso propio sobre el tema (producto del activismo, la afinidad por cuestiones profesionales, cercanía familiar al tema, haber tomado un curso de especialización y / o experiencias que son reconocidas como discriminatorias), esta aparece como el resultado de un proceso "natural" de las sociedades modernas. Para varias entrevistadas, tanto profesionales como universitarias, la posibilidad de acceder a la educación superior y al mercado laboral serían expresión de igualdad de género, lo demás vendría como consecuencia de méritos y capacidades propias.

Respecto de la elección de la carrera profesional, se observan casos en los que el padre influye indirectamente, sobre todo en áreas "masculinizadas", no porque hiciera explícito el deseo que su hija estudiara una determinada carrera, sino por su cercanía con ella desde pequeña. Por ejemplo el padre, que cuenta con estudios en matemáticas, dispone de tiempo para apoyar a la hija en las tareas escolares, para compartir hobbies, gustos, etc.

Luego, la experiencia familiar se articula con la experiencia escolar y el carácter del establecimiento educacional en el cual las 
entrevistadas cursaron sus estudios básicos y secundarios. Esta experiencia puede presentarse sin mayores puntos de quiebre -a menos que la familia haya experimentado una crisis económica que las obliga a cambiarse de colegio, o la separación de los padres, como mencionábamos- y es en el espacio universitario donde se tiende a producir la toma de conciencia respecto de una posición de género. La experiencia universitaria resulta interesante, en cuanto abre espacios para la emancipación (mayor tiempo disponible para estar fuera de la casa), pero también genera ciertas tensiones. Estas se expresan, en algunos casos, como comentarios sexistas en la sala de clases o la necesidad de "cuidarse" de cometer errores frente a los pares:

(...) en la misma facultad hay varios profes que tiran comentarios estúpidos, por ejemplo, hubo uno que estábamos hablando como del funcionamiento de la célula, y llega el profe y dice, "pero si la célula funciona como una lavadora, sí poh, ¿cómo funciona la lavadora? Mujeres quédense calladas", un profesor, y ahí no podís decir nada, porque al final lo mejor es dejar pasar ese comentario y esperar a que ese profe no te dirija nunca la palabra (...) Y el otro que estaba pasando neurología y dice "bueno, estadísticamente los hombres viven menos, porque trabajan más" (...); comentarios como sutiles, pero que tienen un trasfondo igual pesado. (EU, 19 años, estudiante de Licenciatura en Biología, segundo semestre, capas altas)

Se trata de verse enfrentadas a estereotipos respecto de sus capacidades intelectuales y su aspecto físico (belleza vs. inteligencia), que podrían llegar a cuestionar sus capacidades como profesionales. Esto también se manifiesta en las dinámicas con pares -compañeros y compañeras de carrera- y profesores, principalmente en torno a la valoración de los logros académicos: obtener buenas notas, llegar a ser ayudante de un curso, etc. Si bien no todas las entrevistadas manifestaron haber experimentado una situación de estas características, sí existía conocimiento de 
su ocurrencia y un cuestionamiento a las diferencias que eventualmente los profesores (varones) podían hacer entre hombres y mujeres:

(...) tenía compañeros que decían eso, [que] a mí me elegían como ayudante porque era mujer, no porque era capaz, entonces esa fue la discriminación (...), igual tenía compañeras que pensaban eso, como que en verdad me elegían porque era bonita y simpática y pude ser ayudante (...), el profe quería una ayudante, y como era medio jote le gustaba tener ayudantes mujeres, entonces [decían que] por eso me elegían (...); yo soy súper responsable, siempre llegué a la ayudantía a la hora, todas las clases trataba de que todos entendieran, entonces $\mathrm{mi}$ papel de ayudante lo hacía súper bien, entonces nadie tenía que criticarme. O sea, nunca fue algo sospechoso como "pucha esta loca no sabe nada y me está enseñando", no, nunca, siempre todas mis ayudantías que he hecho las he tratado de hacer con el mayor conocimiento posible, nunca tuve ayudantía por tenerla no más, siempre es por saber. (EU, 26 años, estudiante de Ingeniería Civil en Minas, quinto año, capas medias)

\section{La experiencia laboral}

Como mencionamos, si bien encontramos una recepción positiva frente a las nuevas concepciones de género, debido a la desnaturalización de los roles y la ampliación de los derechos de las mujeres, esta recepción no se manifiesta necesariamente en todos los ámbitos de la experiencia, sino en varios casos como una cuestión relativa al acceso al trabajo - por medio del cual se obtiene la independencia económica- y la igualdad de oportunidades económicas, sobre todo entre quienes provienen de sectores medios o cuya familia ha tenido dificultades económicas, ya sea por situación de cesantía del padre, la madre y/o la separación de la pareja. En varios relatos las madres se convirtieron en proveedoras exclusivas, delegando gran parte de las tareas domésticas 
o el cuidado de los hijos en las abuelas -lo que puede generar tensiones por la autoridad en la crianza-, o en otra trabajadora a la cual le pagan si cuentan con los recursos para hacerlo. Sin embargo, el rol de sus madres como trabajadoras y profesionales, y sobre todo como mujeres autónomas, es reconocido por las entrevistadas.

(...) mi mamá ha sido súper chora, independiente, no tiene que darle explicaciones a nadie, aunque haya estado casada, me acuerdo que ella siempre hizo su vida, y así me gustaría ser igual a mí, o sea, no andar dando explicaciones o permisos, no, no. (EU, 27 años, estudiante de Geología, sexto semestre, capas altas)

(...) generacionalmente, de mi mamá siempre se esperó mucho, pero mi mamá no pescó, mi mamá era totalmente rebelde, y también iba por lo mismo, o sea, tuvo una hija tempranamente y ella igual siguió estudiando y sacó la carrera y trabajó sola y vivió sola desde los 21 años, entonces eh, no sé si... no lo he hablado mucho con ella tampoco, pero generacionalmente el entorno le pedía otra cosa, pero ella funcionó más o menos parecido a lo que yo estoy funcionando ahora en torno como a mi rol femenino (...). (EU, 19 años, estudiante de Bachillerato, tercer semestre, capas altas)

En este sentido, entre las profesionales entrevistadas, la importancia de la experiencia laboral no posibilita por sí misma una mejor recepción o mayor disposición frente al discurso de la igualdad de género, pero en varios casos -dependiendo del tipo de actividad desempeñada- aparece como una instancia que puede generar un mayor grado de reflexión sobre situaciones que se consideran discriminatorias - propias o vividas por una amiga o pariente- $y$, por lo tanto, una toma de posición o al menos un malestar y disconformidad frente a un estado de cosas. Y es precisamente entre quienes tienen más años de desempeño laboral que se observa un grado de reflexividad mayor, así como la capacidad 
de reconocer las desigualdades a las que se pueden ver expuestas. Entre ellas se encuentran comentarios sexistas de compañeros de trabajo, diferencias de salario que no tienen justificación entre dos profesionales con la misma calificación y problemas asociados al hecho de ser madres y al cuidado de los hijos, sobre todo si no hay una pareja presente. Así como cuestionamientos al rol de las propias mujeres como compañeras o en cargos de jefatura, su falta de solidaridad (por ejemplo, en relación con las licencias médicas por enfermedad del hijo) y su relación con el poder.

Haremos referencia a dos situaciones específicas, que muestran las paradojas y contradicciones en el modo en que las mujeres se integran al mundo del trabajo: la ausencia de reconocimiento por parte del par masculino y el acoso laboral. En el primer caso, una de las entrevistadas, con formación en ciencias sociales, llega a un equipo de trabajo ya constituido por personas provenientes del área de tecnología y ciencias básicas; en un primer momento, su condición de mujer y asistente social, en ese contexto, la lleva a pensar no se esperaba nada de mí, pero, debido a su entusiasmo por el proyecto que se desarrolla y la posibilidad de imprimirle un carácter social, comienza a elaborar estrategias para ser vista y oída (como cambiar el modo de vestir por uno más formal), lo que ella define como generar "espacios de intervención":

(...) mi compañero de trabajo, no me pescó, yo creo que un año, no me pescaba, es como si yo no existía.

ENT $^{12}:$ ¿No te escuchaba?

E: No me escuchaba, si yo decía algo, lo desvalidaba, como que no era algo significativo. $\mathrm{Y}$ yo empecé como una microestrategia, así como todos los días haciendo pequeñas cosas, lo cateteaba, desde lo más básico, y a veces me decía "ya, de ahí lo veo", y yo me paraba atrás y lo esperaba, y me miraba para atrás y me decía “¿qué

12 ENT: entrevistadora 
estás haciendo ahí?", "es que [nombre compañero], no puedo avanzar sin eso, así que te voy a esperar". (EP, 31 años, asistente social, capas medias)

En su opinión, estas estrategias resultaron exitosas, ya que su compañero, luego de un tiempo, reconoció los privilegios de su posición masculina, y ella pudo ampliar su participación en los proyectos que se estaban desarrollando, así como el reconocimiento de su aporte.

El segundo caso refiere a una situación de "mobbing maternal", esto es, "la violencia o acoso sufrido por la mujer por el hecho de ser madre, especialmente en su lugar de trabajo" (Riquelme, 2011, p. 44). Esta es una forma de acoso psíquico contra las mujeres embarazadas que:

(...) no busca directamente la eliminación de esa mujer de su lugar de trabajo, sino hacerle la vida imposible de tal manera que ella misma y otras trabajadoras a su alrededor, viendo lo que ocurre, no se atrevan a ejercer su derecho a la maternidad. En síntesis, lo que se busca es evitar nuevos embarazos en la empresa. (Op. cit.)

La entrevistada que llegó al cargo de gerenta relata su experiencia en dos empresas donde el discurso social sobre la maternidad y la "declaración de intenciones" se contradice con las prácticas respecto de las trabajadoras y, particularmente, las trabajadoras embarazadas (cambiarlas de oficina, no incluirlas en reuniones, limitar funciones, no recibir mensajes, aislamiento, etc.), aun cuando exista un sistema de protección a la maternidad. Como plantean Ximena Díaz et al., el ingreso creciente de las mujeres al mercado de trabajo en Chile ha generado fuertes tensiones derivadas de la persistencia de un modelo familiar y de relaciones de género que "asigna a las mujeres la responsabilidad del trabajo reproductivo -trabajo doméstico y cuidado no remunerado"-. No obstante, el discurso social sobre la maternidad le otorga a esta un rol fundamental en la sociedad, el trabajo y labores de cuidado de hijos menores "son vistos como una 
interferencia negativa, fundamentalmente por el mito de que la maternidad aumentaría los costos laborales, el ausentismo y la rotación laboral de las mujeres, lo cual incidiría, a su vez, en su productividad" (Díaz, Mauro y Ansoleaga, 2017, p. 46). Esta tensión es la que experimenta la entrevistada:

(...) de repente le cuento a mi jefe que estoy embarazada, mi jefe "sí, ya, bueno, felicitaciones", pero de la boca para afuera. Y un día con ocho meses yo de embarazo, a punto de tener el posnatal, a las ocho y media de la noche en [comuna donde se ubica la empresa] me dice... estábamos revisando unas tarifas de unas tiendas, "¿sabes qué [nombre entrevistada]?, no te noto como comprometida con la pega", y ahí yo le digo "perdón, pero son las ocho y media de la noche en [comuna donde se ubica la empresa] con una guata de ocho meses, no entiendo bien qué entiendes tú por compromiso con la empresa, estamos trabajando". En el fondo, el gallo me empezó como a hacer una especie de hostigamiento ¿cachai?, en un principio me sentí culpable de haber quedado embarazada, ahora, yo lo que converso con amigas de otros lados es que, aunque de repente lleves cinco años en la empresa y quedas embarazada... (EP, 38 años, ingeniera comercial, capas altas, 1 hijo)

La situación la hace sentir "desamparada" y "angustiada", ya que además debía costear la mayor parte de los gastos asociados a su embarazo y a la casa en que viviría con su hijo y su pareja, ya que él tenía menores ingresos. A raíz de ello cuestiona fuertemente el discurso que las empresas manejan sobre la maternidad, dado que, en su opinión, en la práctica todo depende de la relación con los jefes (hombre o mujer) y del apoyo que este pueda brindar, más allá de la normativa vigente, lo que limita las posibilidades de ser madre para las mujeres profesionales que desean avanzar en el desarrollo de su carrera. En un contexto donde además los pares, hombres y mujeres, no necesariamente expresan su apoyo a quienes viven esta forma de acoso: 
Yo tengo pareja, pero hay mujeres que son gerentes y que han optado por ser mamás solas, porque se dedicaron a trabajar, no encontraron esa pareja o se les pasó el tiempo, tengo otra amiga que se inseminó y le salieron dos, sola. Entonces hay mujeres que optamos más tarde por la maternidad porque privilegiamos el tema profesional, entonces la cachetada en la cara cuando tú decides es mucho más fuerte. (...). Claro, ocurre, pero todo el mundo toma palco, ¿cachai?, o sea, en el fondo si yo quiero demandar a la empresa o a este personaje, yo no voy a tener a ningún ni compañero ni compañera a mi lado como para dar la versión, independiente de que le pueda tocar a ella después, porque es normal, todo el mundo cuida su puesto de trabajo, la cosa está complicada, entonces no hay una conciencia colectiva de este tema, o del hostigamiento, bullying (...). (EP, 38 años, ingeniera comercial, capas altas, 1 hijo)

\section{Algunas consideraciones finales}

Como planteábamos al principio, el propósito de este trabajo era reflexionar sobre los significados que mujeres profesionales, así como estudiantes universitarias que están en etapas iniciales y más avanzadas en sus carreras, le atribuyen a la igualdad de género, ya sea en su dimensión discursiva o práctica. Intentamos abordar la cotidianeidad de sus experiencias en el ámbito familiar, educativo y laboral, para comprender de qué modo han tomado forma normas, valores, imágenes y estereotipos respecto de los roles femenino y masculino en Chile durante las últimas décadas. En qué medida las mujeres han incorporado un principio básico de las sociedades democráticas, más allá de los conocimientos teóricos o militancias en organizaciones feministas. Más aún en un contexto como el actual, en el que, a pesar de que la igualdad de género parece ser promovida desde distintos sectores políticos e ideológicos, no necesariamente se traduce en los mismos términos 
para todos ellos ni se promueve en todos los campos, particularmente en aquellos asociados al ejercicio del poder.

Hicimos referencia al género como "campo primario" del poder, pensando precisamente en las dificultades que pueden coexistir para conciliar actitudes, creencias e imaginarios tradicionales acerca de los espacios y atributos asignados a lo masculino y lo femenino, y cómo las fronteras entre ellos se han ido desplazando, pero también reacomodando ante las resistencias y sospechas que todavía existen respecto del trato equitativo que deben recibir las mujeres en todos los ámbitos.

En este sentido, pese a los estereotipos aún presentes y a los temores de las entrevistadas ante la posibilidad de ser mal evaluadas o que sus logros sean cuestionados (la "sospecha" de que lo que obtienen no fue producto del esfuerzo ni el mérito), la igualdad se concibe, como plantea Fraser, como ser un par, interactuar literalmente como un igual con quien es diferente pero no por ello superior. Más que "usurpadoras" -al decir de Montecino- se consideran legítimas habitantes de un lugar ya ganado, pero que exige una actualización permanente en el modo de ocuparlo, nuevos aprendizajes. Desde esa perspectiva, la percepción de ocupar un lugar de modo inadecuado puede no ser experimentada por quienes cuentan con mayores recursos económicos, aunque en sus relatos existe un grado de reflexividad respecto de las distintas posiciones que ocupan hombres y mujeres, de las diferencias entre su experiencia y las de sus madres o abuelas respecto a su desenvolvimiento en el ámbito público y privado. La posibilidad de acceder a estudios superiores, impulsadas por sus propios padres y teniendo como modelo a una madre trabajadora, para desarrollar una carrera profesional, configura un horizonte en el cual el trabajo se vuelve constitutivo de la subjetividad -sin desplazar del todo a la maternidad-, resistiéndose así a las definiciones externas respecto de lo que significa ser una mujer y sus límites de actuación.

Se reconoce entonces que se han producido transformaciones importantes en las relaciones entre hombres y mujeres que inci- 
den en la redefinición de los roles. Uno de los planos en los que se manifiesta con fuerza dicha redefinición es en la autonomía del cuerpo y la vida sexual, así como en la libertad para decidir sobre la maternidad -convirtiéndola en una elección y no un destino-y la importancia o no de estar en pareja para hacerlo. No obstante, esto resulta paradojal, dadas las presiones que experimentan para desarrollarse profesionalmente aquellas que también quieren ser madres. Este tema, al cual hicimos referencia a través de un caso específico de discriminación, estaba presente en el relato de prácticamente todas las entrevistadas: la conciencia de que la maternidad conlleva un costo. De tal modo que, una vez que se es madre, el discurso de la igualdad parece resquebrajarse ante los obstáculos que enfrentan sobre todo aquellas que optan por ser "madres solas" o por una maternidad más tardía.

Desde esta perspectiva, y teniendo en cuenta que no profundizamos más que en algunos aspectos de la experiencia de un grupo acotado de mujeres en el espacio familiar, laboral y educativo, y en los significados que le otorgan a la igualdad de género, llama la atención cómo se reproducen estereotipos y creencias acerca de los roles de género. Cómo la anécdota a la cual no se le ha puesto mucha atención puede cobrar importancia cuando se trata de reflexionar sobre el sexismo y la discriminación. Historias que se repiten, comentarios recibidos que vuelven a la memoria y que podrían ser cuantificables, pero que es necesario también poner en el contexto de historias más amplias, que son las de cada una de las entrevistadas. No obstante, la afirmación de la idea de igualdad y la adhesión a un discurso que la valora tiene su contracara en el temor a que "la diferencia" se disuelva y surja la confusión en el orden de los géneros.

\section{Referencias}

Araujo, K. y Martucelli, D. (2012). Desafíos comunes. Retrato de la sociedad chilena y sus individuos. Tomo I. Santiago de Chile: LOM.

Comisión Nacional de Productividad. (2017). Mujeres en el mundo la- 
boral: Un aporte para Chile. Más oportunidades, crecimiento y bienestar. Participación Laboral Femenina, 26 septiembre. Recuperado en 10 de noviembre de 2017 de http:// www.comisiondeproductividad.cl/wp-content/ uploads/2017/09/Participacion_Laboral_Femenina_26_septiembre.pdf

Cumplido, M. J. (23 de septiembre 2014) El feminismo y la idiotez del término feminazi. El Quinto Poder. Recuperado de http:/ / www.elquintopoder.cl/genero/el-feminismo-y-la-idiotez-del-termino-feminazi/

Delsing, R. (1997). La familia: el poder del discurso. En Discurso, Género y Poder. Discursos públicos: Chile 1978-1993. Santiago de Chile: LOM-ARCIS.

Díaz Berr, X., Mauro Cardarelli, A., Ansoleaga Moreno, E. \& Toro Cifuentes, J. P. (2017). Violencia de género en el trabajo en Chile. Un campo de estudio ignorado. Ciencia \& trabajo, 19(58), 42-48. Recuperado en 10 de noviembre de 2017 de https:/ /dx.doi.org/10.4067/S0718-24492017000100042

Dubet, F. (2011). Repensar la justicia social. Contra el mito de la igualdad de las oportunidades. Buenos Aires: Siglo XXI.

Fraser, N. (2008). Escalas de justicia. Barcelona: Herder Editorial.

Fraser, N. (2013). Feminist Politics in the Age of Recognition: A TwoDimensional Approach to Gender Justice. In Fortunes of feminism: from state-managed capitalism to neoliberal crisis (pp. 159-173). London-New York: Verso.

Godoy Ramos, C. G. (2013). El Estado chileno y las mujeres en el siglo XX. De los temas de la mujer al discurso de la igualdad de géneros. Diálogos Revista Electrónica de Historia, 14(1), 97-123. Recuperado en 19 de noviembre de 2017 de http:/ / www. scielo.sa.cr/scielo.php?script=sci_arttext\&pid=S1409469X2013000100004\&lng=es\&tlng=es.

Godoy Ramos, C. G. (2016). Experiencias y significados de la igualdad de género en dirigentes universitarias: rupturas, adaptaciones y continuidades. Perfiles educativos, 38(154), 118-133. Recuperado en 19 de noviembre de 2017 de http:/ / www.scielo.org.mx/scielo.php?script=sci_arttext\&pid=S0185$26982016000400007 \& \operatorname{lng}=\mathrm{es} \& t \operatorname{lng}=\mathrm{es}$.

Guzmán, V. (2013). Discursos de género e institucionalidad pública. En C. Mora (Ed.), Desigualdad en Chile: la continua relevancia del 
género. Santiago de Chile: Ediciones Universidad Alberto Hurtado.

Hernández, R., Fernández, C. y Baptista, P. (2006). Metodología de la investigación. México D. F.: Mc Graw Hill / Interamericana.

Hurtado, M., Pérez, S. y Dides, C. (2004). El debate sobre derechos sexuales y reproductivos en Chile: ¿Separación Iglesia-Estado? En Diálogos Sur-Sur. Sobre Religión, Derechos y Salud Sexual y Reproductiva: los casos de Argentina, Colombia, Chile y Perú. Santiago de Chile: Universidad Academia de Humanismo Cristiano (UAHC), Progénero.

Montecino, S. (2007) Madres y huachos. Alegorías del mestizaje chileno, Santiago de Chile: Editorial Catalonia.

Mora. C. (ed.) (2013). La imperceptibilidad del género. En Desigualdad en Chile: la continua relevancia del género. Santiago de Chile: Ediciones Universidad Alberto Hurtado

Moulian, T. (2002). Chile actual. Anatomía de un mito, Santiago de Chile: LOM.

OECD. (2016). Panorama de la Sociedad 2016. Un Primer Plano sobre los jóvenes. La situación de Chile. Recuperado el 15 de noviembre de 2017 de https: / / www.oecd.org/chile/sag2016-chile.pdf

Olea, R., Grau, O. y Pérez, F. (2000). El género en apuros. Santiago de Chile: LOM.

Oyarzún, K. (2000) La familia como ideologema. Género, globalización y cultura, Chile, 1989-1997. Revista Chilena de Humanidades, 20. Santiago de Chile: Facultad de Filosofía y Humanidades, Universidad de Chile.

Programa de las Naciones Unidas para el Desarrollo (PNUD). Informe sobre el Desarrollo Humano en Chile 2010. Género: los desafíos de la Igualdad. Santiago de Chile: PNUD.

Riquelme, V. (2011). ¿La maternidad castigada? Discriminación y malos tratos. Aporte al debate $N^{\circ} 25$. Santiago de Chile: Dirección del Trabajo.

Santa Cruz, L. (1995). De la lucha de clases a lucha de género. Santiago de Chile: Libertad y Desarrollo, Serie Opinión Política N 41.

Scott, J. (1990). El género: una categoría útil para el análisis histórico. En Nash y Amelang (Eds.) Historia y género: las mujeres en la Europa moderna y contemporánea. Valencia: Alfons el Magnanim. 
Théry, I. (2004). Dynamique de légálite de sex et transformations de la parenté en Femmes, genre et societés. L'etat des savoirs. Paris: La découverte.

Thumala. M.A. (2007). Riqueza y piedad. El catolicismo de la elite económica chilena. Santiago de Chile: Random House Mondadori.

Tironi, E. (2003). ¿Es Chile un país moderno? En E. Tironi et al., Cuánto y cómo cambiamos los chilenos. Balance de una década. Censos 1992-2002. Santiago de Chile: INE-Comisión Bicentenario.

Tironi, E. (2005). El sueño chileno. Familia, comunidad y nación en el Bicentenario. Santiago de Chile: Aguilar Chilena Ediciones.

UN-CEPAL. (2010). ¿Qué Estado para qué igualdad?: XI Conferencia Regional sobre la Mujer de América Latina y el Caribe. Brasilia, 13 al 16 de julio de 2010. Santiago de Chile: CEPAL.

Undurraga, R. (2013). Mujer y trabajo en Chile: ¿Qué dicen las mujeres sobre su participación en el mercado laboral? En C. Mora (Ed.) Desigualdad en Chile: la continua relevancia del género. Santiago de Chile: Ediciones Universidad Alberto Hurtado.

Valdés, X., Caro, P., Saavedra, R., Godoy, C., Rioja, T. y Raymond, E. (2006). ¿Modelos Familiares emergentes o fractura del modelo tradicional? En Puertas adentro. Femenino y masculino en la familia contemporánea. Santiago de Chile: LOM.

Valdés S. X. (2007a). La vida en común. Familia y vida privada en Chile y el medio rural en la segunda mitad del siglo XX. Santiago de Chile: LOM.

Valdés S., X. (2007b). Lo privado y lo público: Lugares de desigual disputa. Mesa Agenda Progénero Chile 21, p.20 Recuperado el 18 de enero de 2010 de http:/ / www.fes.cl/documentos / Genero/ximenavaldes_progenero.pdf

Vergara, P. (1985). Auge y caída del neoliberalismo en Chile. Santiago de Chile: FLACSO. 